\title{
Borsa İstanbul'da İşlem Gören Enerji Firmalarının Hisse Senedi Getirilerine Etki Eden Finansal Faktörler (Financial Factors Affecting the Stock Returns of the Energy Firms Enlisted in Istanbul Stock Exchange)
}

\section{Şahnaz KOÇOĞLU (iDa Cihan TANRIÖVEN (Db}

a Ankara Hacı Bayram Veli Üniversitesi, İktisadi ve İdari Bilimler Fakültesi, Ankara, Türkiye. sahnaz.kocoglu@hbv.edu.tr

a Ankara Hacı Bayram Veli Üniversitesi, İktisadi ve İdari Bilimler Fakültesi, Ankara, Türkiye. c.tanrioven@hbv.edu.tr

\begin{tabular}{|c|c|}
\hline MAKALE BİLGİSİ & ÖZET \\
\hline Anahtar Kelimeler: & Amaç - Bu çalışma insan kaynağının büyük öneme sahip olduğu otel işletmelerinde çalışan \\
\hline Hisse senedi getirisi & $\begin{array}{l}\text { Amaç - Bu çalışmanın amacı Borsa İstanbul'da işlem gören enerji firmalarının hisse senedi } \\
\text { getirilerine etki eden sirket finansal verilerini analiz etmektir. }\end{array}$ \\
\hline Enerji & \\
\hline Panel veri analizi & $\begin{array}{l}\text { Yöntem - Hisse senedi getirilerine etki edebilecek faktörler olarak firma büyüklüğü, satışlar, } \\
\text { faalivet karı ve kısa vadeli borclar belirlenmis ve analiz kapsamına Akenerii Elektrik Üretim }\end{array}$ \\
\hline Firma büyüklüğü & A.Ş., Aksa Enerji Üretim A.Ş., Aksu Enerji ve Ticaret A.Ș., Ayen Enerji A.Ş. ve Zorlu Enerji \\
\hline Kısa vadeli borç & $\begin{array}{l}\text { Elektrik Üretim A.Ş. firmaları alınmıştır. Belirlenen gelir tablosu ve bilanço verilerinin bir önceki } \\
\text { döneme göre değişiminin, finansal tabloların açılandığı dönemdeki hisse senedi getirisindeki }\end{array}$ \\
\hline Gönderme Tarihi 1 Ekim 2018 & artışa ya da azalışa etkisi panel veri analizi yöntemine göre araştırılmıştır. \\
\hline Revizyon Tarihi 10 Mart 2019 & Bulgular - Bir önceki döneme göre kısa vadeli borçlardaki değişimin hisse senedi getirileri \\
\hline Kabul Tarihi 20 Mart 2019 & $\begin{array}{l}\text { üstünde ters yönlü ve anlamlı, satış hacmindeki değişimin ise aynı yönlü ve anlamlı bir etki } \\
\text { gösterdiği ortaya konmuştur. Sonuç olarak, enerji sektöründe faaliyet gösteren firmaların hisse }\end{array}$ \\
\hline \multirow{2}{*}{$\begin{array}{l}\text { Makale Kategorisi: } \\
\text { Araştırma Makalesi }\end{array}$} & $\begin{array}{l}\text { senedi getirilerine kısa vadeli borçlardaki artışın olumsuz, satışlardaki artışın ise olumlu etki } \\
\text { gösterdiği tespit edilmiştir. }\end{array}$ \\
\hline & $\begin{array}{l}\text { Tartışma - Türkiye'de faaliyet gösteren enerji firmalarının hisse senedi getirilerinin, sistematik } \\
\text { olmayan risk faktörlerinden kısa vadeli borçlardaki değişime ve satış hacmindeki değişime } \\
\text { duyarlı olduğu ortaya konmuştur. }\end{array}$ \\
\hline
\end{tabular}

\begin{tabular}{ll}
\hline ARTICLE INFO & ABSTRACT \\
\hline $\begin{array}{l}\text { Keywords: } \\
\text { Stock return }\end{array}$ & $\begin{array}{l}\text { Purpose - In this study, financial factors affecting the stock returns of energy companies } \\
\text { enlisted in Istanbul Stock Exchange are examined. } \\
\text { Energy }\end{array}$ \\
$\begin{array}{l}\text { Design/methodology/approach - Factors that might have effect on the stock returns are } \\
\text { identified and firm size, sales revenue, operating profit and short-term liabilities are chosen. }\end{array}$ \\
$\begin{array}{l}\text { Firm size } \\
\text { senerji, Aksa, Aksu, Ayen and Zorlu which are enlisted in Istanbul Stock Exchange are }\end{array}$ \\
$\begin{array}{l}\text { selected for the analysis. How the change in the factors affects the stock returns of energy } \\
\text { companies is examined through panel data analysis method. }\end{array}$ \\
$\begin{array}{l}\text { Findings - The results revealed that the change in the short-term liabilities has negative and } \\
\text { statistically meaningful effect on the stock returns. Moreover, the change in the sales revenue } \\
\text { Revised 10 March 2019 }\end{array}$ \\
$\begin{array}{l}\text { has positive and statistically meaningful effect on the returns. To sum up, an increase in the } \\
\text { short-term liabilities has negative while an increase in the sales revenue has positive effect on } \\
\text { the stock returns of energy firms in Turkey. } \\
\text { Discussion - The stock returns of energy firm enlisted in Istanbul Stock Exchange are affected } \\
\text { by the unsystematic risk factors found as change in the total sales and the current liabilities. }\end{array}$ \\
Research Article
\end{tabular}

\section{Giriş}

Enerji alanında faaliyet gösteren firmaların hisse senedi getirilerini etkileyen faktörler birçok makaleye konu olmuştur. Hamilton (1983) tarafından yapılan çalışmanın, petrol fiyatlarının makroekonomiye etkisini kanıtlamasıyla, petrol fiyatları literatürde her yönüyle incelenmiş ve enerji firmalarının hisse senedi getirilerine petrol fiyatlarının etkisi de araştırmacılar tarafından en çok incelenen alanlardan birisi olmuştur. Fakat enerji firmalarının hisse senedi getirilerine etki eden sistematik olmayan, her bir şirkete özel faktörün etkisi yeterince araştıılmamıştır. Bu çalışmanın amacı, Türkiye'de faaliyet gösteren enerji firmalarının hisse 
senedi getirilerine, bilanço ve gelir tablosu verilerinin etkisini incelenmektir. Bu amaçla Borsa İstanbul'da işlem gören enerji firmalarının hisse senedi getirilerine, firma büyüklügünün, satışların, karın ve kısa vadeli borçların etkisini ölçmek amacıyla panel veri analizi yapılmıştır. Çalışmada, öncelikle enerji firmalarının hisse senedi getirilerini etkileyen faktörler üstüne yapılan çalışmalar paylaşılmıştır. Daha sonra, çalışmada kullanılan veriler, analiz yöntemi ve analiz sonuçları paylaşılmıştır. Son bölümde, çalışmanın literatüre katkısı ve gelecekte yapılacak olan araştırmalara nasıl yol gösterebileceği açıklanmıştır.

\section{Literatür}

Literatürde petrol ve doğal gaz üretimi yapan enerji firmalarının hisse senedi fiyatları ile ilgili birçok çalışma mevcuttur. Sadorsky (2001) Kanadalı firmalarla ilgili yaptığı çalışma ile literatürde öncü olmuştur ve petrol fiyatları ve kur gibi makroekonomik faktörlerin petrol ve doğal gaz şirketlerinin hisse senedi fiyatları üstünde etkisi olduğunu göstermiştir. Ewing, Malik ve Ozfidan (2002) benzer bir çalışmayla petrol ve doğal gaz endüstrisindeki en büyük şirketleri temsil eden endeksler üstünde bir çalışma yapmışlar ve oynaklıklarını incelemişlerdir. Sonuç olarak da, doğal gaz pazarındaki oynaklığın bir şok sonrasında petrol pazarındakinden daha uzun sürdügünü göstermişlerdir. Hammoudeh, Dibooglu ve Alesia (2004) ABD için yaptıkları çalışmada petrol firmalarının hisse senedi getirilerini tahmin etmede petrole dayalı türev araçların (future) kullanılabileceğini göstermiştir. Enerji şirketi olarak doğal gaz ve petrol şirketlerini inceleyen ve petrol fiyatlarının hisse senedi getirileri üstüne etkisi olduğunu gösteren bir çalışma da Shaharudin, Samad ve Bhat(2009) tarafından ABD, İngiltere ve Hindistan için yapılmıştır. Bu çalışmaların aksine Mohanty, Nandha ve Bota (2010) Orta ve Doğu Avrupa için benzer bir çalışma yapmış ve petrol fiyatlarının etkisini gözlemlememişlerdir. Arouri ve Nguyen (2010) Avrupa'daki petrol ve gaz şirketlerinin petrol fiyatlarına karşı duyarlı olduğunu tespit etmişlerdir. Mohanty ve Nandha (2011) Doğu Avrupa için gözlemleyemedikleri ilişkiyi, Amerikan petrol ve doğal şirketleri için bulmuşlar, hisse senetlerinin petrol fiyatlarından etkilendiği sonucuna ulaşmışlardır. Ramos ve Veiga (2011) enerji firmaları içinden petrol ve gaz şirketlerine yoğunlaşmış ve birçok ülke için petrol fiyatlarının etkisine bakmışlardır. Sonuç olarak petrol fiyatlarının gelişmiş ülkelerdeki gaz ve petrol şirketleri için daha büyük bir risk oluşturduğu sonucuna varmışlardır. Sklavos, Dam ve Scholtens (2013) enerji firmalarının likiditesini detaylı olarak incelemiş ve petrol fiyatlarındaki artışın enerji hisselerindeki işlem hacmini azalttığını ve likidite ölçütü olarak spread üstünde negatif etkisi olduğunu göstermiştir. Sonuç olarak, Hamilton (1983) petrol fiyatlarının önemini kanıtladığından bu yana, asıl ilgi alanı petrol ve doğal gaz şirketleri ve petrol fiyatlarının bu firmalarının hisse senedi fiyatlarına etkisi olmuştur. Koçoğlu ve Tanrı̈ven (2016) çalışmasında görülebileceği gibi, petrol ve doğal gaz şirketlerinden sonra literatürdeki ilgi yenilenebilir enerji üreten firmalara yoğunlaşmıştır. Ana faaliyet alanı petrol ve doğal gaz çıkarmak ve işlemek ya da yenilenebilir enerji üretimi olmayan enerji firmaların, hisse senedi fiyatlarına etki eden sistematik olmayan faktörlerle ilgili yeterli çalışma bulunmamaktadır. Enerji firmalarının hisse senedi getirileri üstünde makroekonomik değişkenlerden ziyade firma özelindeki faktörleri inceleyen bir çalışma Boyer ve Filion (2007) tarafından yapılmıştır. Boyer ve Filion çalışmalarında Kanada'da faaliyet gösteren enerji firmalarının hisse senedi getirileri üstünde operasyonel nakit akımlarının, kanıtlanmış rezervlerin ve toplam üretimin etkisi olduğunu bulmuşlardır. Fakat hala enerji firmalarının hisse senedi getirileri üstüne etki eden, petrol fiyatı, doğal gaz fiyatı ya da faiz oranları gibi makroekonomik faktörler dışında firma özelindeki faktörlerin etkisini incelemiş yeterli çalışma bulunmamaktadır. Bu çalışmanın amacı da, net petrol ve doğal gaz ithalatçısı olan bir ülke olarak Türkiye'de faaliyet gösteren enerji firmalarının hisse senedi getirilerine etki eden bilanço ve gelir tablosu verilerini analiz etmektir.

\section{Veriler ve Analiz}

Bu çalışmada Borsa İstanbul'da işlem gören Akenerji Elektrik Üretim A.Ş., Aksa Enerji Üretim A.Ş., Aksu Enerji ve Ticaret A.Ş., Ayen Enerji A.Ş. ve Zorlu Enerji Elektrik Üretim A.Ş. kullanılmış, enerji alanında faaliyet gösteren fakat analiz dönemini kapsayacak yeterli verisi olmayan firmalar çalışma dışı bırakılmıştır. Analizlerin yapıldığı zaman aralığı, 2012 Ocak-2017 Haziran ayı arası, 3 aylık dönemler olarak belirlenmiştir. Enerji firmalarının bilanço ve gelir tablosu verileri Kamuyu Aydınlatma Platformundan (www.kap.org.tr), firmaların hisse senedi fiyat verileri Datastream programından elde edilmiştir. Verilerin analizinde Excel ve Eviews 7 programları kullanılmıştır. Çalışma kapsamında kullanılan verilerin özeti aşağıdaki tabloda paylaşılmıştır. 
Tablo 1: Çalışma Kapsamında Kullanılan Veriler

\begin{tabular}{ll}
\hline Değişkenler & Açılklamalar \\
\hline$\Delta \mathbf{K B}$ & $\begin{array}{l}\text { 3 aylık dönem bilanço verilerinden elde edilen kısa vadeli borçların bir önceki döneme } \\
\text { göre değişimi }\end{array}$ \\
\hline$\Delta \mathbf{F K}$ & $\begin{array}{l}\text { 3 aylık dönem gelir tablosu verilerinden elde edilen esas faaliyet karı/zararı kaleminin bir } \\
\text { önceki döneme göre değişimi }\end{array}$ \\
\hline$\Delta \mathbf{S H}$ & $\begin{array}{l}\text { 3 aylık dönem gelir tablosu verilerinden elde edilen satış hacmi kaleminin bir önceki } \\
\text { döneme göre değişimi }\end{array}$ \\
\hline$\Delta \mathbf{F B}$ & $\begin{array}{l}\text { 3 aylık dönem bilanço verilerinden elde edilen toplam varlıklar kaleminin bir önceki } \\
\text { döneme göre değişimi }\end{array}$ \\
\hline$\Delta \mathbf{R}$ & $\begin{array}{l}\text { 3 aylık toplam günlük hisse senedi getirilerinin bir önceki } 3 \text { aylık toplam getiriye göre } \\
\text { değişimi }\end{array}$ \\
\hline
\end{tabular}

Çalışma kapsamında, firma büyüklügünü temsilen toplam varlıklar kalemi ve kısa vadeli finansal yükümlülüklerinin etkisini temsil amacıyla kısa vadeli borçlar kalemi bilançolardan elde edilmiştir. Gelir tablosundan ise, finansal performansını değerlendirmek amacıyla, faaliyet karı/zararı (esas faaliyet karı/zararı) kalemi ve satış hacmi kalemi kullanılmıştır. Bu amaçla, 2012 Ocak ayı ile 2017 Mart ayı arasında 21 adet 3 aylık finansal tablolarından veriler çekilmiştir. Gelir tablosundan elde edilen veriler için, bir sonraki dönem açıklanan finansal tabloda farklılık olması durumunda, veriler son açılama doğrultusunda yenilenmiştir. Fakat elde edilen verilerin, tek başına temsil gücü zayıf olmasından dolayı, tüm finansal tablo verilerinin bir önceki döneme göre değişimi hesaplanmıştır ve firma performansı değerlendirmesi için, bilanço ve gelir tablosundaki trend göz önünde bulundurulmaya çalışılmıştır. Sonuç olarak 2012 2. Dönem ile 2017 1. Dönem arasında bulunan toplam 20 adet finansal tablo dönemi analize dahil edilmiştir.

Hisse senedi getirileri için ise enerji firmalarının günlük fiyat verileri üstünden hesaplamalar yapılmıştır. Bu amaçla, 2 Ocak 2012, 30 Haziran 2017 tarihleri arasındaki günlük hisse senedi getirileri hesaplanmıştır. Daha sonra her 3 aylık dönem için, günlük hisse senedi getirileri toplanmış ve dönemlik toplam getiri elde edilmiştir. Yine finansal tablolarda olduğu gibi bir önceki döneme göre değişimi hesaplanmıştır. Hisse senedi getirileri ile finansa tablo verileri eşleştirilirken bir farklılık uygulanmıştır ve finansal tablo verileri, bir sonraki dönem hisse senedi verileri ile eşleştirilmiştir. Misal, firmanın Ocak-Şubat-Mart ayı için açıkladığı finansal tablo verilerinin etkisi için, Nisan, Mayıs Haziran dönemi hisse senedi getirileri kullanılmıştır. Bunun nedeni, firmaların finansal tablolarını, dönem bittikten sonra 1-2 ay içinde açıklamalarıdır. Ocak-Şubat-Mart ayları için hesaplanan finansal tablo verileri, ancak nisan mayıs aylarında açıklanmakta ve doğal olarak asıl etkisi Nisan-Mayıs-Haziran dönemi hisse senedi getirileri üstüne olmaktadır. Bu nedenle, hisse senedi getirileri için 2012 2. Dönem ile 2017 2. Dönem arası olmak üzere 21 adet dönem kullanılmıştır. Bir önceki döneme göre değişim alındığından, analize, 2012 3. Dönem ile 20172. dönem arasındaki toplam 20 dönem analize dahil edilmiştir.

Bir sonraki aşamada, enerji sektöründe faaliyet gösteren firmaların hisse senedi getirilerine, firma büyüklüğünün, satışların, karın ve kısa vadeli borçların etkisini incelemek amacıyla Panel Veri Analizi yöntemi kullanılmıştır. Aşağıdaki eşitlikte, kullanılan model paylaşılmıştır.

$\Delta \mathrm{R}_{\mathrm{it}}=\mathrm{a}+\beta_{\text {it }} \Delta \mathrm{KB}+\beta_{\mathrm{it}} \Delta \mathrm{FK}+\beta_{\mathrm{it}} \Delta \mathrm{FB}+\beta_{\mathrm{it}} \Delta \mathrm{SH}+\varepsilon$

$\mathrm{i}=$ Firma

$\mathrm{t}=$ Zaman

$\mathrm{KB}=$ Kısa Vadeli Borçlar

$$
\Delta \mathrm{KB}=\frac{K B_{t}-K B_{t-1}}{K B_{t-1}}
$$

$\mathrm{FK}=$ Faaliyet $\mathrm{Kar} 1$

$$
\Delta \mathrm{FK}=\frac{\mathrm{FK}_{t}-\mathrm{FK}_{t-1}}{\mathrm{FK}_{t-1}}
$$

$\mathrm{FB}=$ Firma Büyüklüğü 


$$
\Delta \mathrm{FB}=\frac{\mathrm{FB}_{t}-\mathrm{FB}_{t-1}}{\mathrm{FB}_{t-1}}
$$

$\mathrm{SH}=$ Satış Hacmi

$$
\Delta \mathrm{SH}=\frac{\mathrm{SH}_{t}-\mathrm{SH}_{t-1}}{\mathrm{SH}_{t-1}}
$$

$\mathrm{R}=$ Hisse Senedi Getirisi

$$
\Delta \mathrm{R}=\frac{\mathrm{R}_{t}-\mathrm{R}_{t-1}}{\mathrm{R}_{t-1}}
$$

Panel veri analizinin yapılabilmesi için, öncelikle veriler üstünde birim kök testleri yapılmalıdır. Sabitli Model için sonuçlar Tablo 2'de paylaşılmıştır. Levin, Lin ve Chu(2002), Im, Pesaran ve Shin (2003) testlerinde, tüm seriler için veri setinde birim kök vardır hipotezi reddedilmiştir. Fisher(1932) türü Maddala ve $\mathrm{Wu}(1999)$ ve Choi (2001) birim kök testi olan ADF ve PP testleri sonucunda da, veri setlerinde birim kök tespit edilmemiştir. Fakat Hadri (2000) birim kök testleri sonucunda, veri setlerinin bir kısmında birim kök bulunmuştur.

İkinci model olarak, sabitli ve trendli birim kök testi uygulanmıştır ve sonuçlar Tablo 3'te görülmektedir. Bu kez de sadece kısa vadeli borçlar serisinde Levin, Lin ve Chu(2002) testi sonucunda birim kök bulunmuştur. Ayrıca yüzde beş istatistiksel anlamlılık seviyesinde, faaliyet karı, firma büyüklüğü, satış hacmi ve hisse senedi getirisi serilerinde Breitung (2001) testi sonucunda birim kök bulunmuştur. Genel bir değerlendirme yapılmıştır ve görüldügü üzere, tüm testler göz önünde bulundurulduğunda, sonuçların çok büyük kısmı serilerin hiç birinde birim kök olmadığını belirtmiştir. Bunun sonucunda, veri seti panel veri analizi yapmaya uygun olarak değerlendirilmiştir.

Tablo 2: Birim Kök Testi Sonuçları-Sabitli

\begin{tabular}{lccccc}
\hline & $\begin{array}{c}\text { Kisa Vadeli } \\
\text { Borçlar }\end{array}$ & $\begin{array}{c}\text { Faaliyet } \\
\text { Karı }\end{array}$ & Firma Büyüklüğü & $\begin{array}{c}\text { Satış } \\
\text { Hacmi }\end{array}$ & $\begin{array}{c}\text { Hisse Senedi } \\
\text { Getirisi }\end{array}$ \\
\hline Levin, Lin \& Chu t & -2.480 & -5.127 & -2.771 & -6.028 & -3.634 \\
& $(0.00)$ & $(0.00)$ & $(0.00)$ & $(0.00)$ & $(0.00)$ \\
\hline Im, Pesaran \& Shin W- & -4.120 & -3.649 & -3.684 & -5.306 & -3.693 \\
ist. & $(0.00)$ & $(0.00)$ & $(0.00)$ & $(0.00)$ & $(0.00)$ \\
\hline ADF - Fisher Ki-Kare ist. & 36.392 & 34.897 & 32.587 & 45.947 & 34.212 \\
& $(0.00)$ & $(0.00)$ & $(0.00)$ & $(0.00)$ & $(0.00)$ \\
\hline PP - Fisher Ki-Kare ist. & 103.186 & 113.142 & 65.755 & 156.555 & 50.549 \\
& $(0.00)$ & $(0.00)$ & $(0.00)$ & $(0.00)$ & $(0.00)$ \\
\hline Hadri Z-ist & 1.804 & 0.810 & -0.274 & 0.235 & 1.825 \\
& $(0.03)$ & $(0.20)$ & $(0.608)$ & $(0.406)$ & $(0.034)$ \\
\hline Heteroscedastic & 2.193 & 2.407 & 0.566 & 1.038 & 1.895 \\
Consistent Z-ist & $(0.01)$ & $(0.00)$ & $(0.285)$ & $(0.149)$ & $(0.029)$ \\
\hline
\end{tabular}

Tablo 3: Birim Kök Testi Sonuçları-Sabitli ve Trendli

\begin{tabular}{lccccc}
\hline & $\begin{array}{c}\text { Kisa Vadeli } \\
\text { Borçlar }\end{array}$ & $\begin{array}{c}\text { Faaliyet } \\
\text { Karı }\end{array}$ & $\begin{array}{c}\text { Firma } \\
\text { Büyüklüğ̈ }\end{array}$ & $\begin{array}{c}\text { Satıs } \\
\text { Hacmi }\end{array}$ & $\begin{array}{c}\text { Hisse Senedi } \\
\text { Getirisi }\end{array}$ \\
\hline Levin, Lin \& Chu t & -1.022 & -3.872 & -2.144 & -5.403 & -2.641 \\
& $(0.15)$ & $(0.00)$ & $(0.01)$ & $(0.00)$ & $(0.00)$ \\
\hline Breitung t-ist & -2.10228 & -0.193 & -0.551 & -0.564 & 2.478 \\
& $(0.01)$ & $(0.42)$ & $(0.29)$ & $(0.28)$ & $(0.99)$ \\
\hline Im, Pesaran \& Shin W-ist & -3.322 & -2.736 & -2.204 & -3.809 & -2.263 \\
& $(0.00)$ & $(0.00)$ & $(0.01)$ & $(0.00)$ & $(0.01)$ \\
\hline ADF - Fisher Ki-Kare ist. & 28.322 & 28.489 & 22.363 & 32.160 & 25.625 \\
& $(0.00)$ & $(0.00)$ & $(0.01)$ & $(0.00)$ & $(0.00)$ \\
\hline PP - Fisher Ki-Kare ist. & 86.988 & 72.227 & 54.110 & 51.963 & 48.167 \\
& $(0.00)$ & $(0.00)$ & $(0.00)$ & $(0.00)$ & $(0.00)$ \\
\hline Hadri Z-ist & 10.234 & 2.001 & 3.771 & 3.150 & 10.841 \\
& $(0.00)$ & $(0.022)$ & $(0.00)$ & $(0.00)$ & $(0.00)$ \\
\hline Heteroscedastic Consistent Z-ist & 8.515 & 8.382 & 6.253 & 5.958 & 8.470 \\
& $(0.00)$ & $(0.00)$ & $(0.00)$ & $(0.00)$ & $(0.00)$ \\
\hline
\end{tabular}


Panel veri analizinde, 3 ayrı model uygulanmıştır. İlk model en küçük kareler yöntemi olmuştur. Bu analizin sonuçları Tablo 4'te paylaşılmıştır. Analizin sonucunda, enerji firmalarının hisse senedi getirilerine istatistiksel olarak anlamlı seviyede etki eden ilk faktör kısa vadeli borçlardaki değişim olmuştur ve etkinin negatif olduğu yani artan kısa vadeli borcun hisse senedi getirindeki değişime negatif etki ettiği görülmektedir. İstatistiksel olarak anlamlı bir etki gösteren diğer faktör, satış hacmindeki değişim olmuştur ve hisse senedi getirisindeki değişime etkisi olumlu olarak görülmüştür. Fakat analiz sonucu, $\mathrm{R}^{2}$ 0,06 bulunmuş ve modelin uygunluğu testi sonucunda F istatistiği \%10 seviyesinde anlamlı bulunmamıştır.

Tablo 4: En Küçük Kareler Panel Veri Analizi Sonuçları

\begin{tabular}{lcccc}
\hline & Katsayı & $\begin{array}{c}\text { Standard } \\
\text { Hata }\end{array}$ & $\begin{array}{c}\mathbf{t} \\
\text { İstatistiği }\end{array}$ & Olasılık \\
\hline Kısa Vadeli Borçlar & -6.949 & 3.810 & -1.823 & 0.071 \\
\hline Faaliyet Karı & -0.037 & 0.146 & -0.257 & 0.797 \\
\hline Firma Büyüklü̆̈̈̈ & -14.072 & 17.003 & -0.827 & 0.410 \\
\hline Satış Hacmi & 0.407 & 0.183 & 2.222 & 0.028 \\
\hline $\mathbf{C}$ & 1.454 & 1.775 & 0.819 & 0.414 \\
\hline $\mathbf{R}^{2}$ & 0.066 & & & \\
\hline Adj. $\mathbf{R}^{2}$ & 0.027 & & & \\
\hline F istatistiği & 1.700 & & & \\
\hline
\end{tabular}

Diğer model olarak, sabit etkili model ile panel veri analizi yapılmış olup sonuçlar Tablo 5 'te paylaşılmıştır. $\mathrm{Bu}$ model sonucunda da benzer sonuçlar elde edilmiştir. Kısa vadeli borçlardaki değişim negatif etki yaparken, satış hacmindeki değişim hisse sendi getirilerindeki değişime pozitif etki yapar bulunmuştu. Diğer değişkenler açısından istatistiksel olarak anlamlı bir etki bulunmamıştır.

Tablo 5: Sabit Etkili Panel Veri Analizi Sonuçları

\begin{tabular}{lcccc}
\hline & Katsayı & $\begin{array}{c}\text { Standard } \\
\text { Hata }\end{array}$ & t İstatistiği & Olasılık \\
\hline Kisa Vadeli Borçlar & -7.751 & 3.796 & -2.041 & 0.044 \\
\hline Faaliyet Karı & 0.005 & 0.148 & 0.038 & 0.969 \\
\hline Firma Büyüklüğ̈ & -11.335 & 17.025 & -0.665 & 0.507 \\
\hline Satış Hacmi & 0.331 & 0.184 & 1.794 & 0.076 \\
\hline $\mathbf{C}$ & 1.612 & 1.764 & 0.914 & 0.363 \\
\hline $\mathbf{R}^{2}$ & 0.120 & & & \\
\hline Adj. $\mathbf{R}^{2}$ & 0.043 & & & \\
\hline F istatistiği & 1.564 & & & \\
\hline
\end{tabular}

Tablo 6: Rastsal Etkili Panel Veri Analizi Sonuçları

\begin{tabular}{|c|c|c|c|c|}
\hline & Katsayı & $\begin{array}{c}\text { Standard } \\
\text { Hata }\end{array}$ & $\begin{array}{c}\mathbf{t} \\
\text { İstatistiği }\end{array}$ & Olasılık \\
\hline Kısa Vadeli Borçlar & -6.949 & 3.778 & -1.839 & 0.069 \\
\hline Faaliyet Karı & -0.037 & 0.145 & -0.259 & 0.795 \\
\hline Firma Büyüklüğ̈̈u & -14.072 & 16.862 & -0.834 & 0.406 \\
\hline Satış Hacmi & 0.407 & 0.181 & 2.240 & 0.027 \\
\hline $\mathrm{C}$ & 1.454 & 1.760 & 0.826 & 0.410 \\
\hline $\mathbf{R}^{2}$ & 0.066 & & & \\
\hline Adj. $R^{2}$ & 0.027 & & & \\
\hline F istatistiği & 1.700 & & & \\
\hline
\end{tabular}

Bu modelde de $\mathrm{R}^{2}$ 0,12 iken, F istatistiğine göre model bu analiz için uygun bulunmamıştır. Rastsal Etkili Panel Veri Analizi sonucu Tablo 6'te verilmiştir. Diğer iki model ile benzer sonuçlar elde edilmiştir. $\mathrm{R}^{2}$ düşük çımıştır ve $\mathrm{F}$ istatistiğine göre model uygun bulunmamıştır. Bu aşamada, Rastsal Etkili ya da Sabit Etkili Model arasında hangisinin daha uygun olduğuna karar verebilmek için Hausman (1978) testi yapılmış. Hausman (1978) testi sıfır hipotezi, Rastsal Etkiler Modelinin daha uygun olduğudur. 
Tablo 7'de paylaşılan sonuçlara göre, sıfır hipotezi kabul edilmelidir. Yani rastsal etkiler modeli analiz için daha uygundur. Çıkan sonuçlar genel olarak değerlendirildiğinde, ekonomik teori ile uyumludur.

Tablo 7: Hausman Testi Sonuçları

\begin{tabular}{lll}
\hline & Ki Kare İstatistiği & Olasılık \\
\hline Hausman Test & 5.595 & 0.231 \\
\hline
\end{tabular}

Enerji firmalarının kısa vadeli borçlarındaki artış, hisse senedi getirilerini olumsuz etkilemektedir. Satışlardaki artış ise, enerji firmalarının hisse senedi getirilerini olumlu etkilemektedir. Sonuçlar ile ilgili tek sıkıntı F istatistiğinin anlamlı bulunmamasıdır. Bu nedenle, panel veri analizi sadece iki bağımlı değişkenle, kısa vadeli yabancı kaynaklardaki değişimler ve satış hacmindeki değişim ile tekrar yapılmıştır. Bağımlı değişkenleri sadece kısa vadeli borçlardaki değişim ve satış hacmindeki değişim olan En Küçük Kareler Modeli sonuçları Tablo 8'de görülmektedir.

Tablo 8: En Küçük Kareler Panel Veri Analizi Sonuçları

\begin{tabular}{lcccc}
\hline & Katsayı & $\begin{array}{c}\text { Standart } \\
\text { Hata }\end{array}$ & $\begin{array}{c}\mathbf{t} \\
\text { İstatistiği }\end{array}$ & Olasılık \\
\hline Kısa Vadeli Borçlar & -7.537 & 3.704 & -2.034 & 0.044 \\
\hline Satış Hacmi & 0.432 & 0.179 & 2.410 & 0.017 \\
\hline $\mathbf{C}$ & 0.947 & 1.654 & 0.572 & 0.568 \\
\hline $\mathbf{R}^{\mathbf{2}}$ & 0.059 & & & \\
\hline Adj. $\mathbf{R}^{2}$ & 0.040 & & & \\
\hline F istatistiği & $3.095(0,04)$ & & & \\
\hline
\end{tabular}

() F istatistiği P değeri

Tablo 9: Sabit Etkili Panel Veri Analizi Sonuçları

\begin{tabular}{lcccc}
\hline & Katsayı & $\begin{array}{c}\text { Standard } \\
\text { Hata }\end{array}$ & $\begin{array}{c}\text { T } \\
\text { İstatistiğ }\end{array}$ & Olasıllk \\
\hline Kısa Vadeli Borçlar & -8.284 & 3.685 & -2.247 & 0.026 \\
\hline Satış Hacmi & 0.352 & 0.180 & 1.951 & 0.054 \\
\hline $\mathbf{C}$ & 1.202 & 1.642 & 0.732 & 0.465 \\
\hline $\mathbf{R}^{\mathbf{2}}$ & 0.116 & & & \\
\hline Adj. $\mathbf{R}^{2}$ & 0.059 & & & \\
\hline F istatistiğ & $2.040(0,06)$ & & & \\
\hline
\end{tabular}

Her iki değişken için de sonuçlar anlamlı bulunmuş ve F istatistiği \% 10 istatistiksel anlamlılık seviyesinde anlamlı bulunmuştur. İkinci model olarak Sabit Etkili Panel Veri Analizi Yapılmıştır. Sonuçların görülebileceği Tablo 9'a göre, kısa vadeli borçlardaki değişimler ve satış hacmindeki değişimler hisse senedi getirisindeki değişimlere anlamlı bir etki göstermektedir. F istatistiğine göre bu model de yapılan analiz için uygun bir model olmuştur.

Son olarak Tablo 10'da Rastlar Etkili Panel Veri Analizi sonuçları verilmiştir. Analiz sonuçlarına göre, bağımlı değişkenlerin etkisi istatistiksel olarak anlamlı bulunmuş ve $\mathrm{F}$ istatistiğine göre de model uygun bulunmuştur.

Tablo 10: Rastsal Etkili Panel Veri Analizi Sonuçları

\begin{tabular}{lcccc}
\hline & Katsayı & $\begin{array}{c}\text { Standard } \\
\text { Hata }\end{array}$ & $\begin{array}{c}\text { T } \\
\text { İstatistiği }\end{array}$ & Olasılık \\
\hline Kısa Vadeli Borçlar & -7.537 & 3.668 & -2.054 & 0.042 \\
\hline Satış Hacmi & 0.432 & 0.177 & 2.434 & 0.016 \\
\hline $\mathbf{C}$ & 0.947 & 1.638 & 0.578 & 0.564 \\
\hline $\mathbf{R}^{2}$ & 0.059 & & & \\
\hline Adj. $\mathbf{R}^{2}$ & 0.040 & & & \\
\hline F istatistiği & $3.095(0,04)$ & & & \\
\hline
\end{tabular}


Tablo 10: Hausman Testi Sonuçları

\begin{tabular}{lll}
\hline & Ki Kare İstatistiği & Olasıllık \\
\hline Hausman Test & 5.826 & 0.054 \\
\hline
\end{tabular}

Tablo 10'da Hausman testi sonuçları paylaşılmıştır. Test sonuçlarına göre, Sabit Etkili Panel Veri Analizi bu model için daha uygun bulunmuştur. Sonuç olarak, kısa vadeli borçlardaki Değişimlerin hisse senedi getirisindeki değişime etkisi negatif olurken, satış hacmindeki değişimin etkisi pozitif olarak bulunmuştur. Bulunan sonuçlar, ekonomik teori ile de uyum içerisindedir. Borçlardaki artış, hisse senedi getirilerini negatif etkilemekte fakat satış hacmindeki artış hisse senedi getirilerini olumlu etkilemektedir.

\section{Sonuç}

Bu çalışmada, Borsa İstanbul'da işlem gören, Akenerji Elektrik Üretim A.Ş., Aksa Enerji Üretim A.Ş., Aksu Enerji ve Ticaret A.Ş., Ayen Enerji A.Ş. ve Zorlu Enerji Elektrik Üretim A.Ş. firmalarının hisse senedi getirilerine firma büyüklügünün, satışların, karın ve kısa vadeli borçların etkisi incelenmiştir. Bu amaçla, panel veri analizi yöntemi kullanılmıştır. Öncelikle birim kök testleri yapılmış ve verilerin panel veri analizine uygunluğu test edilmiştir. Daha sonra, kısa vadeli borçlar, faaliyet karı, firma büyüklüğü ve satış hacminin etkisinin incelendiği en küçük kareler panel veri analizi sabit ve rastsal etkili modeller için ayrı ayrı yapılmıştır. Her 3 modelde, kısa vadeli borçlar ve satış hacmi istatistiksel olarak anlamlı bulunmuştur. Fakat modelin uygunluğunu ölçen $\mathrm{F}$ istatistiğinin anlamlı çıkması için, sadece satış hacmi ve kısa vadeli borçlar için modeller tekrar çalıştırılmıştır. Model istatistiksel olarak uygun bulunmuştur ve kısa vadeli borçlar ile satış hacmi istatistiksel olarak anlamlı çımıştır. Sonuç olarak, Borsa İstanbul'da işlem gören enerji firmalarının hisse senedi getirileri üstünde, bir önceki döneme kıyasla kısa vadeli borçlardaki ve satış hacmindeki değişim etki etmektedir. Kısa vadeli borçlardaki değişim etkisi olumsuz iken, satış hacmindeki değişim etkisi olumlu olarak ortaya konmuştur. Boyer ve Filion(2007) tarafından yapılan çalışmaya benzer şekilde sistematik olmayan risk faktörlerinin de hisse senedi getirileri üstünde etki gösterdiği ortaya konmuştur. Özellikle toplam satışlar ve kısa vadeli borçlardaki değişimlerin, enerji firmalarının hisse senedi getirileri üstündeki etkileri yatırımcılar tarafından göz önünde bulundurulmalıdır. Kısa vadeli borçlarda artış, enerji firmalarının kısa vadede likidite sorunu yaşayabileceği şeklinde piyasada algılanmaktadır. atışların artışı ise, olumlu bir etki olarak piyasalar tarafından kabul görmektedir. Sonraki çalışmalarda, Borsa İstanbul'da işlem gören enerji firmalarını hisse senedi verilerine etki eden faiz oranları, kurdaki değişim, petrol ve doğal gaz fiyatlarındaki değişim gibi sistematik risk unsurları ile şirkete özel faktörlerin toplam etkisi ölçülebilir. Ayrıca, hisse senedi getirilerine etki ile beraber, hisse senedi oynaklığına etkisi de incelenmelidir.

\section{Kaynakça}

Levin, A., Lin, C. F., \& Chu, C. S. J. (2002). Unit root tests in panel data: asymptotic and finite-sample properties. Journal of econometrics, 108(1), 1-24.

Im, K. S., Pesaran, M. H., \& Shin, Y. (2003). Testing for unit roots in heterogeneous panels. Journal of econometrics, 115(1), 53-74.

Maddala, G. S., \& Wu, S. (1999). A comparative study of unit root tests with panel data and a new simple test. Oxford Bulletin of Economics and statistics, 61(S1), 631-652.

Choi, I. (2001). Unit root tests for panel data. Journal of international money and Finance, 20(2), 249-272.

Hadri, K. (2000). Testing for stationarity in heterogeneous panel data. The Econometrics Journal, 3(2), 148161.

Breitung, J. (2001). The local power of some unit root tests for panel data. In Nonstationary panels, panel cointegration, and dynamic panels (pp. 161-177). Emerald Group Publishing Limited.

Hausman, J. A. (1978). Specification tests in econometrics. Econometrica: Journal of the Econometric Society, 1251-1271.

Fisher, R. (1932) Statistical Methods for Research Workers. London: Oliver and Boyd. 
Sadorsky, P. (2001). Risk factors in stock returns of Canadian oil and gas companies. Energy economics, 23(1), 17-28.

Ewing, B. T., Malik, F., \& Ozfidan, O. (2002). Volatility transmission in the oil and natural gas markets. Energy Economics, 24(6), 525-538.

Hammoudeh, S., Dibooglu, S., \& Aleisa, E. (2004). Relationships among US oil prices and oil industry equity indices. International Review of Economics \& Finance, 13(4), 427-453.

Shaharudin, R. S., Samad, F., \& Bhat, S. (2009). Performance and volatility of oil and gas stocks: A Comparative Study on Selected O\&G Companies. International Business Research, 2(4), 87.

Mohanty, S., Nandha, M., \& Bota, G. (2010). Oil shocks and stock returns: The case of the Central and Eastern European (CEE) oil and gas sectors. Emerging Markets Review, 11(4), 358-372.

Arouri, M. E. H., \& Nguyen, D. K. (2010). Oil prices, stock markets and portfolio investment: evidence from sector analysis in Europe over the last decade. Energy Policy, 38(8), 4528-4539.

Mohanty, S. K., \& Nandha, M. (2011). Oil risk exposure: the case of the US oil and gas sector. Financial review, 46(1), 165-191.

www.kap.org.tr, Kamuyu Aydınlatma Platformu, Giriş Tarihi Ağustos 2017.

Ramos, S. B., \& Veiga, H. (2011). Risk factors in oil and gas industry returns: International evidence. Energy Economics, 33(3), 525-542.

Sklavos, K., Dam, L., \& Scholtens, B. (2013). The liquidity of energy stocks. Energy Economics, 38, 168-175.

Koçoğlu, Ş., \& Tanrı̈ven, C. (2016). Alman Borsalarında İşlem Gören Alternatif Enerji Firmalarının Fiyatlarına Etki Eden Faktörler. Ordu Üniversitesi Sosyal Bilimler Araştırmaları Dergisi, 6(3), 895-902

Hamilton, J. D. (1983). Oil and the macroeconomy since World War II. Journal of political economy, 91(2), 228-248.

Boyer, M. M., \& Filion, D. (2007). Common and fundamental factors in stock returns of Canadian oil and gas companies. Energy Economics, 29(3), 428-453. 